\title{
Straddle Robot Design and control with a PID controller optimized by PSO algorithms
}

\author{
Youcef ZENNIR, Sami GRIEF, Elarkam MECHHOUD
}

$(1,2,3)$ Université 20 Août 1955, Automatic Laboratory of Skikda, Skikda, Algeria y.zennir@univ-skikda.dz; samigrief@gmail.com; e.mechhoud@univ-skikda.dz

\begin{abstract}
The work presented in this paper illustrates the design and control of a straddle robot-type four-wheel moving robot with PID controller adjusted by meta-genetic algorithms genetic Algorithm (GA) and PSO. The approach used for the simulation is a modeless approach because it assumes no knowledge of the mathematical model of the system, indeed, the mechanical structure was implemented under SolidWorks, then a simulation (Solidworks, Simulink) has was conducted using particle swarm optimization (PSO) techniques for controller parameter optimization (PID) to control the steering angle and angular velocity of each wheel. The results obtained clearly illustrate the effectiveness of the selected control architecture and the accuracy is better with the use of the PSO algorithm. In a future work, we compare the results with using other optimization algorithms like GA (Genetic Algorithm) and GWO (Grey Wolf Optimizer) algorithm.
\end{abstract}

Keywords: Straddle Mobile robot, Simulink, Solidworks, PID controller, Particle Swarm Optimization, implementation

\section{INTRODUCTION}

Today, human beings and industrial systems are increasingly in need of robots, whatever their types and structures, in order to perform complex tasks, at risk and inaccessible by human beings and which require a certain level of robustness, precision and speed with tasks that are repeated an $\mathrm{N}$ number of times [1-3].

There are as many robots with different types and structures for different tasks to perform and others not yet. We have mobile wheeled robots (2 wheels, 3 wheels and 4 wheels), manipulator robots, walking robots, flying robots, marine robots (figure 1)[4-5].

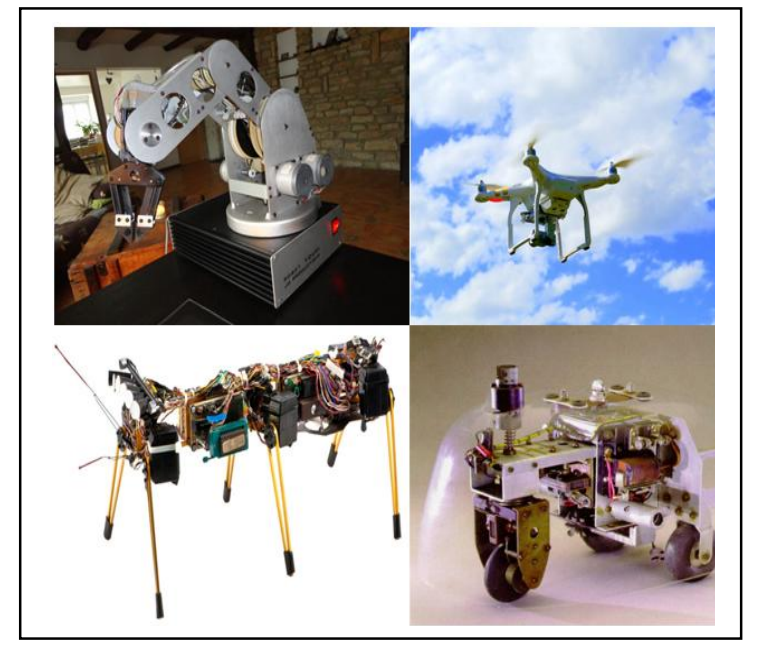

Fig.1. different type of robots
Each type is used for a specific task built for it. The fields of application are very broad, such as medicine, agriculture, the food industry, in scientific research in space (walking robot)[6]. In the field of agriculture there is a robot with four wheels used in very large fields in order to make operations of roses, pickings or other with a possibility of turning on the spot with motors controls the legs and motors controls the wheels (Straddle robot) figure 2 [7-9].

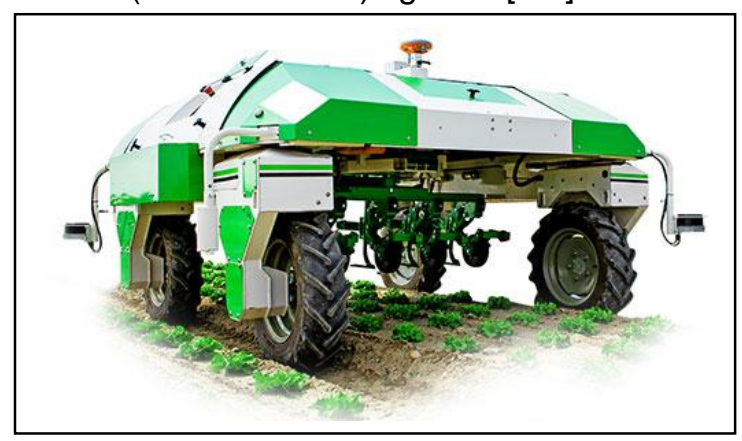

Fig.2. example of Straddle robot

Moving of this robot requires a high level of precision and speed in a specific and difficult environment. Hence our work aims to make a prototype of this robot and propose an architecture control based on a classic PID controller to control the position of the legs and another controller to control the speed of the wheels. The parameters of the controllers will be adjusted and optimized by metaheuristic algorithms (PSO)[9-11]. The work is organized as follows: geometrical modeling, modeling under solidworks and simulink is presented in 
section 2, the control design described in section 3 . In section 4 different simulations and tests carried out are presented and implementation of the robot with control algorithms. Finally section5 is the conclusion.

\section{MODELING OF STRADDLE ROBOT (ROBOT4)}

The Straddle robot is made up of four legs and the body is shaped like a rectangle. Each leg is controlled by a servo motor to control its position. On each leg there is a wheel controlled by a DC motor. This robot is represented geometrically by the following figure:

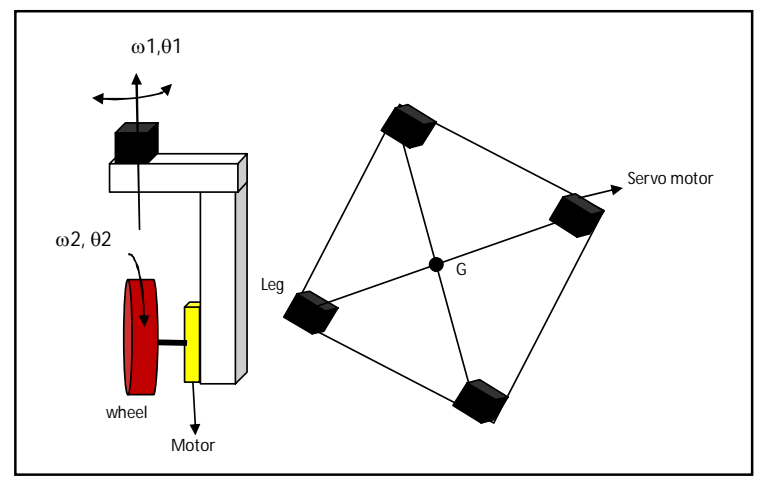

Fig.3. Geometrical model of Straddle robot (ROBOT4)

There is much software for conception in $3 D$ model of any mechanical system or robot [12]. In this work we have used solidworks to developed different parts of the robot shown in the following figure:

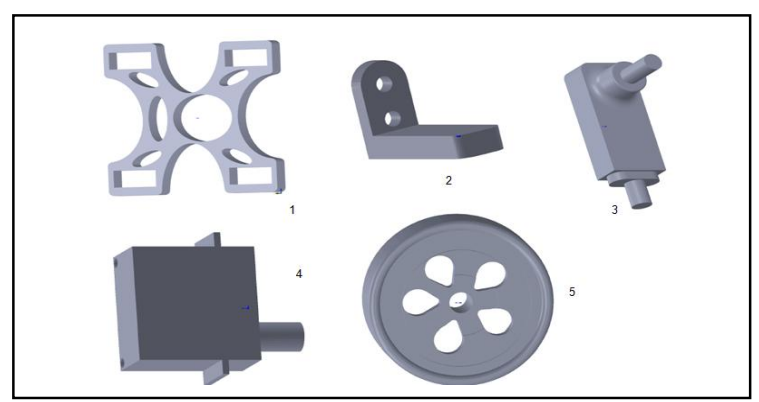

Fig.4. different component model of Straddle robot (1: The chassis, 2: leg (Suspension), 3: DC motor, 4: servo motor, 5: wheel)

After the various components of the robot have been made, assembly is possible provided that the different constraints of movement and the width between the different components are well defined. The operation is repeated for each leg then assemble everything with the chassis. The following figure represents the prototype under solidworks of our robot (ROBOT4).

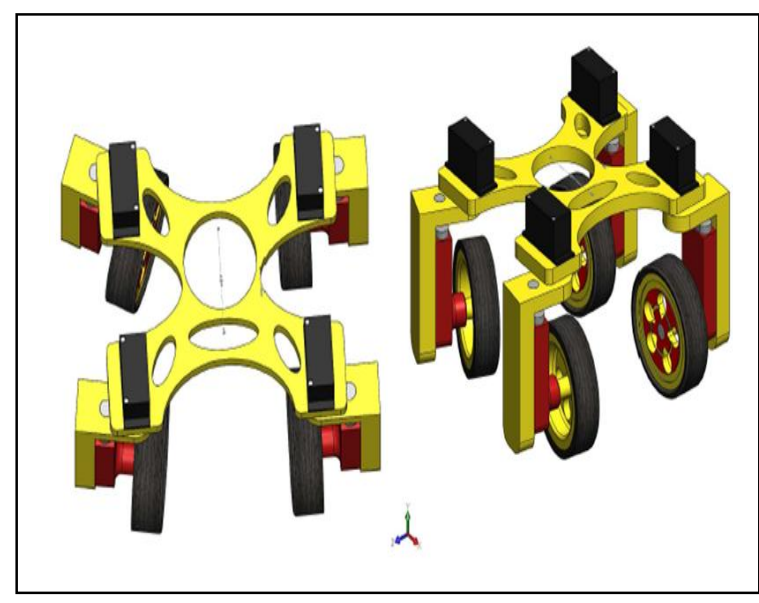

Fig.5. ROBOT4 under Solidworks

Simscape is Simulink's physical and multiphysical modeling platform. We will find physical components in the form of a physical modeling block in the category, the Simscape world to model electronic, mechanical, hydraulic and thermal systems [13]. The Simscape libraries are:

- SimDriveLine: transmission systems.

- SimElectronics: electronic systems.

- SimHydraulics: hydraulic systems.

- SimMechanics: mechanical systems.

With the SimMechanics library and matlab we get the simulink model which allows us to control the robot and simulate the different speeds and positions[13]. The obtained model is illustrated in figure 6.

trme This block represents a joint with a degree of freedom of rotation.

和 This block represents the global repusitury in a model.

This block applies a time invariable traıııvınation between two frames.

\section{CONTROL DESIGN}

in order to control our robot (ROBOT4) either relative to the position of the dropouts and either relative to the speed of the wheels, two PID type controllers parallel for each dropout and wheel (figure 6). Hence we have a total of eight controllers with 24 parameters to adjust[14]. 


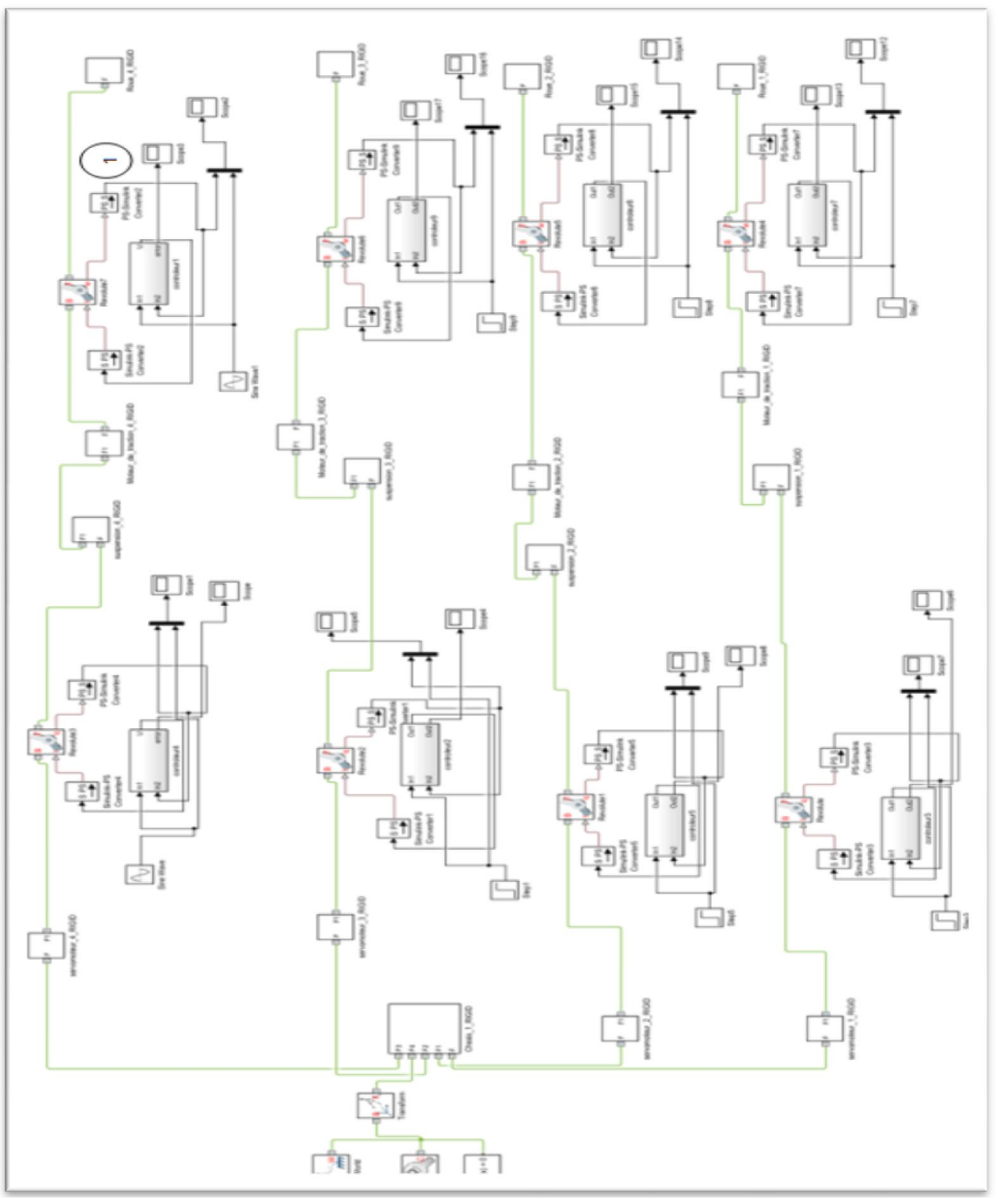

Fig.6. Block diagram in Simulink of ROBOT4

In the literature, there are several methods of adjusting the parameters of the PID controllers, either in the time or frequency domain [14]. In this work we use more efficient metaherestic methods such as Optimization by particulate swarms (PSO)[15-17]. The PSO algorithm is illustrated in figure 7.

In PID controller design methods, the most common performance criteria are integrated absolute error (IAE), the integrated of time weight square error (ITSE), integrated of squared error (ISE) and Mean Square Error (MSE) [15-17]. In this work we use parallel
$\mathrm{PID}$, and the coefficients $\mathrm{Kp}, \mathrm{Ki}, \mathrm{Kd}$ are determined by the PSO algorithm using ITSE performance criteria (figure 5). 


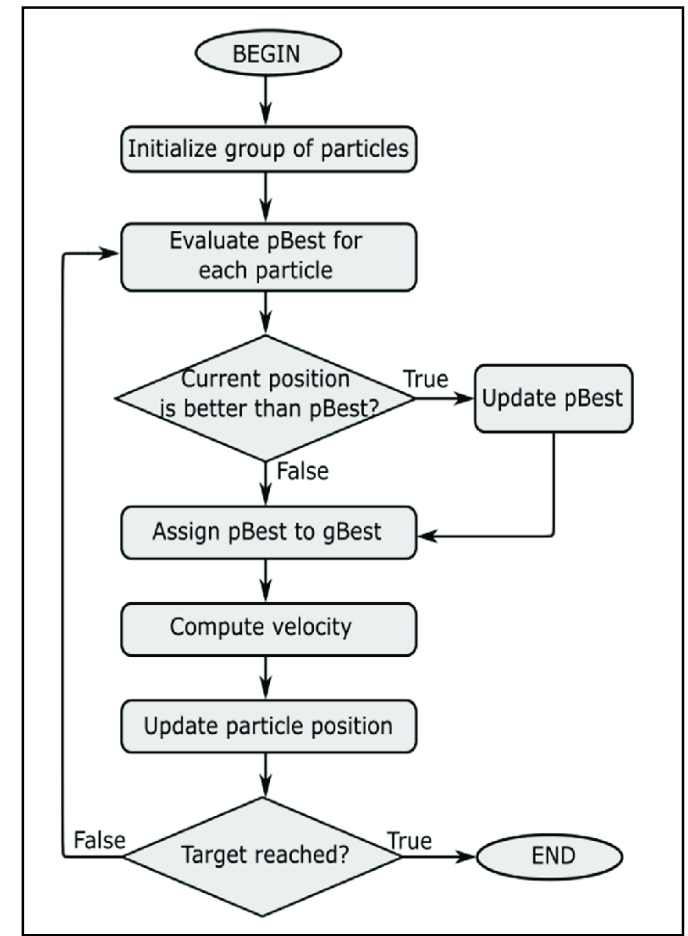

Fig.7. PSO algorithm [15-17]

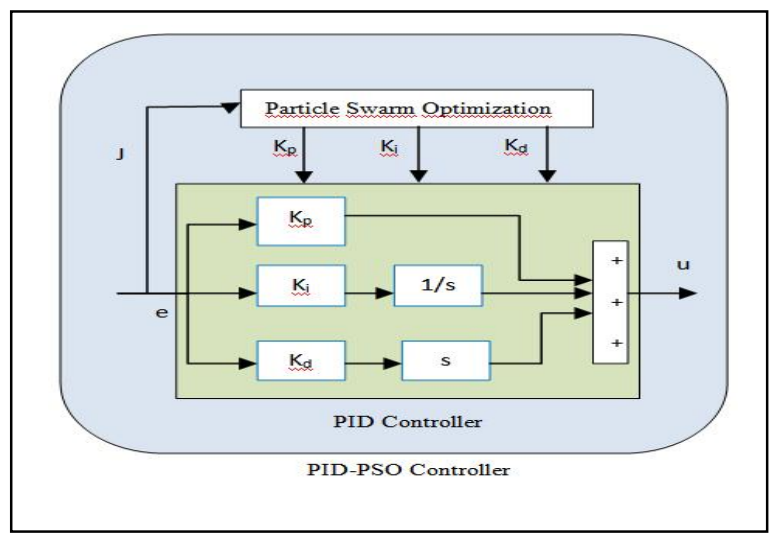

Fig.8. PSO-PID block diagram [9]

\section{SIMULATION}

The simulation is based on parameters tuning of the two controllers for wheel 1 (same operation will be for the other wheels) with four tests:

Table 1. Parameters of simulations

\begin{tabular}{|l|l|l|l|l|}
\hline Test & $\begin{array}{l}\text { Size } \\
\text { of } \\
\text { population } \\
\mathbf{N}^{\circ} \\
\text { iteration }\end{array}$ & $\mathbf{K p}$ & $\mathbf{K i}$ & $\mathbf{K d}$ \\
\hline $\mathbf{1}$ & 10 & 23.04 & 0.003 & 0.002 \\
\hline $\mathbf{2}$ & 20 & 76.96 & 49.7535 & 0.002 \\
\hline $\mathbf{3}$ & 30 & 15.70 & 0.0002 & 0.0003 \\
\hline $\mathbf{4}$ & 40 & 55.70 & 0.0001 & 0.00001 \\
\hline
\end{tabular}

The obtained results are illustrated in the following figures:

- Test 1 :
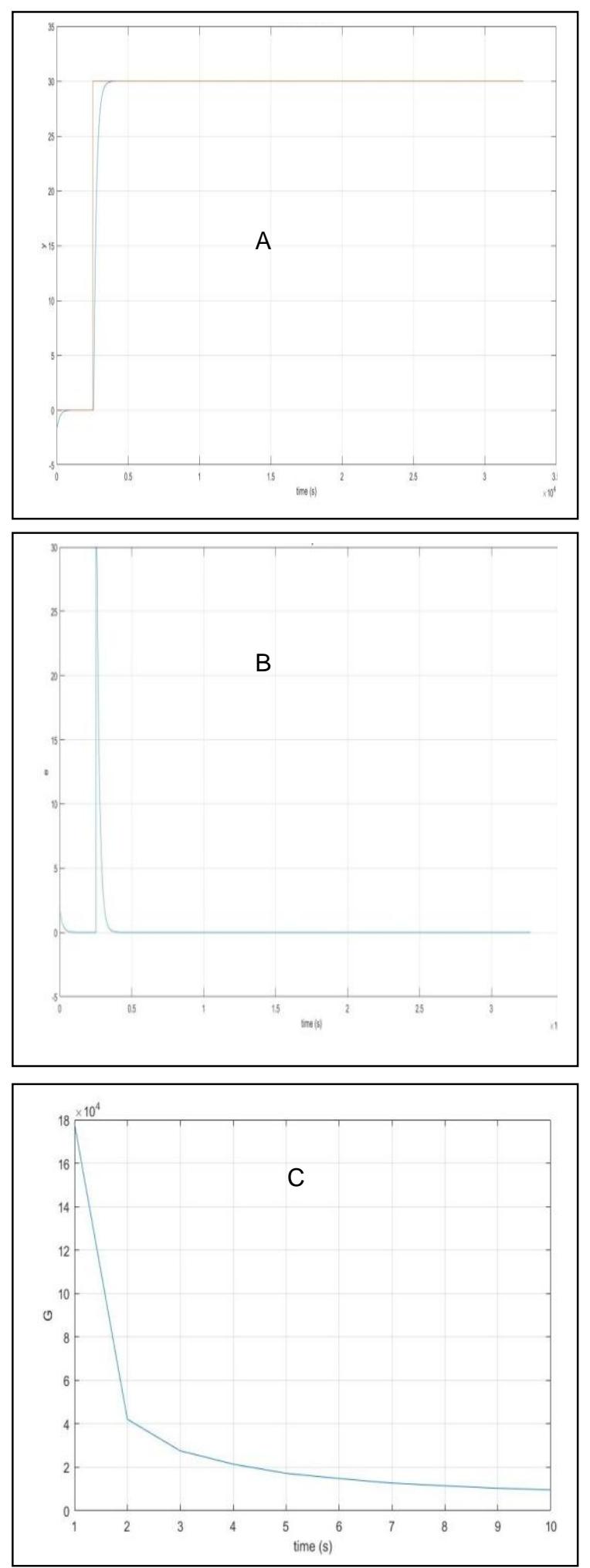

Fig.9. The output and reference input (A), error curve $(B)$ and cost function $(C)$ 
- Test 2 :
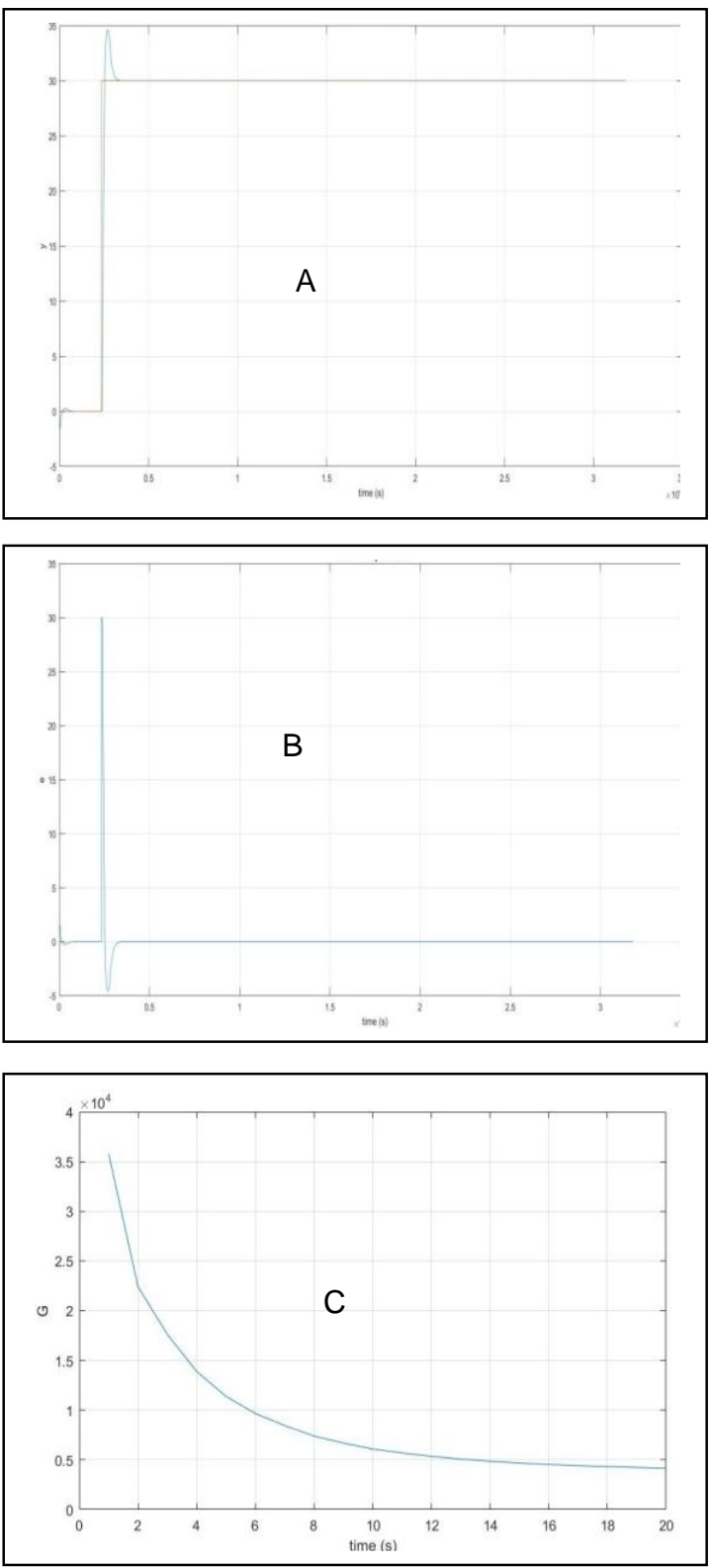

Fig.10. The output and reference input $(A)$, error curve (B) and cost function (C)

The following table illustrates all the obtained results:

Table 2: The obtained results

\begin{tabular}{|l|l|}
\hline Test & Error \\
\hline $\mathbf{1}$ & $-4.3510-7$ \\
\hline $\mathbf{2}$ & $1.5710-7$ \\
\hline $\mathbf{3}$ & $-4.4410-8$ \\
\hline $\mathbf{4}$ & $4.1510-8$ \\
\hline
\end{tabular}
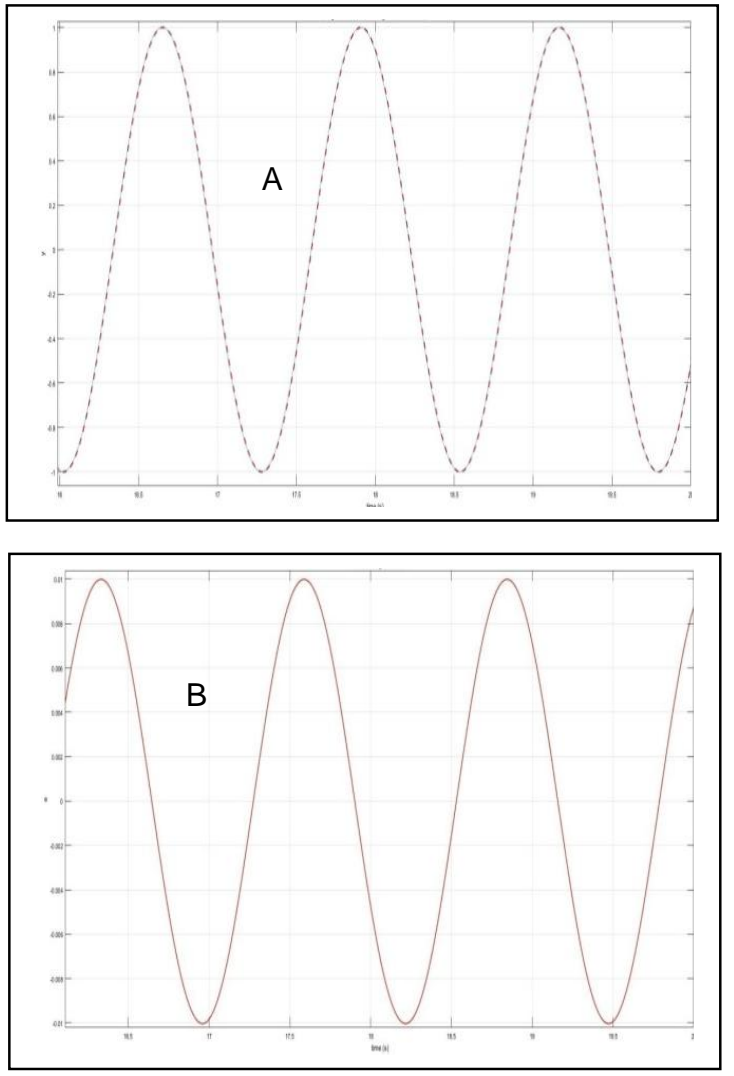

Fig.11. Output and reference input curve (A), error curve (B) with servo motor.

The obtained results show that the tuning with PSO algorithm give very interesting results with very small error and settling time is very small too. Real design of our robot (ROBOT4) is illustrated by the following figure:

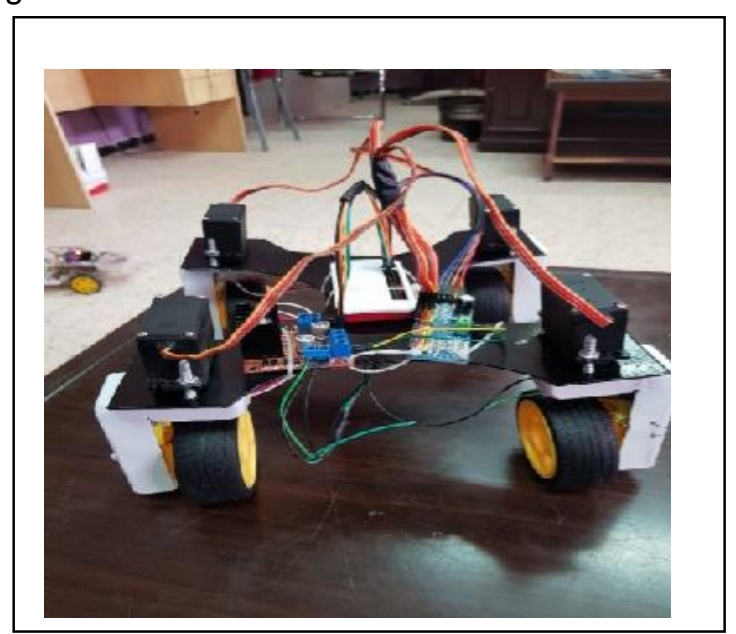

Fig.12. Prototype of ROBOT4.

The Raspberry Pi cart is used to control the robot and its programming by python, Servo motor Tower Pro MG 996R, DC motor, PWM driver PCA9685. The weight is an important 
factor because it plays the role of a resistant torque for the motors. The greater the weight, the slower the speed. The total weight is $2,080 \mathrm{Kg}$.

\section{CONCLUSION}

In this work, we presented the design and control of a straddle robot (RBOBOT4). We presented at the beginning the geometric model and the development of a 3D prototype under the solidworks software. The use of Matlab and the simmechanics library made it possible to obtain a model under simulink which was used to verify the control architecture used (PID tuning with PSO). The simulation results are very interesting with regard to the tracking error and the settling time. We presented the robot made and controlled with a raspberry $\mathrm{PI}$ card and programmed in python. We will study in the future work, the obstacle avoidance problem and the optimization of the control with other algorithm like Genetics algorithm (GA) and GWO algorithm

\section{References:}

[1] Bruno Siciliano, Lorenzo Sciavicco, LuigiVillani, Giuseppe Oriolo, "Robotics: Modelling, Planning and Control", Livre, 2000, pp.632.

[2] Laetitia Matignon,"Introduction à la robotique", Cours, Université de Caen France, 2012, pp.61.

[3] Hela Ben Said,"Navigation autonome et commande référencée capteurs de robots d'assistance à la personne",Thèse de doctorat, université de limoge, 2018, pp.171.

[4] P. Vieyres, "Contribution à la navigation de robots mobiles : approche par modèle direct et commande prédictive", thèse de doctorat, Université d'Orléans, 2009, pp.137.

[5] Slimane Noureddine, "Système de Localisation pour Robots Mobiles", thèse de doctorat, Université de Batna, 2005, pp.114.

[6] Heddouche Kamel, "Etude et conception d'un Robot marchant", Mémoire de master,
Université Mohamed Khider, Biskra, 2014, pp.126

[7] Bernard Bayle, "Robotique Mobile", Cours, Université de Strasbourg, 2011, pp.93

[8] G. Baille, P. Garnier, H.Mathieu, R. PissardGibollet, "Le CyCab de L'INRIA Rhône-Alpes", Rapport technique $n^{\circ}$ 0229, Service Robotique-INRIA, Avril 1999, pp.91

[9] Zennir, Y., Mechhoud, E-A., Seboui, A., Bendib, R., 2017. " Multi-controller approach with PSO- PI $\lambda D \mu$ Controllers for a Robotic Wrist". The $5^{\text {th }}$ International Conference on Electrical Engineering - Boumerdes (ICEE-B), October 29-31, Boumerdes, Algeria, p.7.

[10] Al-Mayyahi, A., 2015. "Path Tracking of Autonomous Ground Vehicle Based on Fractional Order PID Controller Optimized by PSO“, IEEE 13th International Symposium on Applied Machine Intelligence and Informatics, January 22-24, Slovakia, pp.109-114.

[11] Turki, Y. A. Abdulkareem, A. A.,2012. " PSO-based Optimum Design of PID Controller for Mobile Robot Trajectory Tracking ", International Journal of Computer Applications, vol.47, no.23, pp.30-35.

[12] Patrick Gillet, "Conception assistée par ordinateur (CAO) ", Techniques de l'Ingénieur, document 7300 , pp.66.

[13] Belatel Mimi, "Réalisation d'un Logiciel de Prototypage sous Matlab", Thèse de Doctorat, Université Mentouri Constantine, 2009, pp.94.

[14] Henri Bourlès et Hervé Guillard, "Commande des systèmes. Performance et robustesse", Ellipses, 2012

[15] Clerc M.,Kennedy J, "The Particle Swarm: Explosion, Stability and Convergence in a Multi- Dimensional complex Space", IEEE Transactions on Evolutionary Computation, vol. 6, 2001.

[16] Van den Bergh F., "An Analysis of Particle Swarm Optimizers", PhD Thesis, Department of Computer Science, University of Pretoria, South Africa, 2006,pp.300

[17] Kennedy J. and Eberhart R. "Particle Swarm Optimization", In Proceedings of IEEE International Conference on Neural Networks, Perth, Australia, vol. 4, 1995,pp.1942-1948 